\title{
POETRY
}

\section{Morning prayer}

on a street without birds or church bells dusky light streams through windows to cast a serene puddle about the little girl.

on the threshold

onlookers stand as stone:

steel gazes fixed on a delicate face as moon slivers of blue iris

flicker beneath heavy, swollen lids.

the little girl inhales

through thin, lavender lips:

an orchid unfolding

in forceful rhythm,

marked by the sharp rise and fall

of a soft, ballooning belly.

an ellipse forms around her:

hands clasp hands,

glances dodge glances, then redirect

to pierce the borders which enclose them at once curious, then resigned.

heavy breaths fill her chest

to beyond what it can hold.

her belly withdraws beneath her ribs a subtle, gradual surrender.

in the shadows

glances bend towards one another,

meet briefly

then fracture, fragment, drop as glass -

shards pooling amongst hesitant soles.

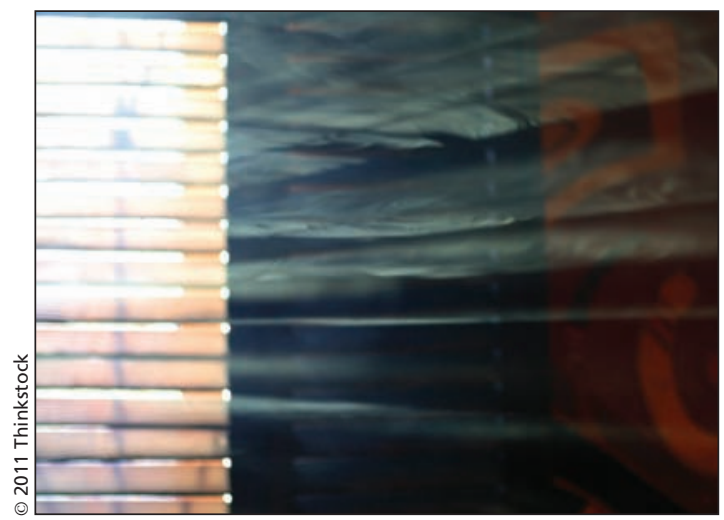

gold rays penetrate dust,

fall gently to anoint white cheeks

with a hint of blush,

then slip softly beyond the threshold.

fingers steeple,

glances soften, melt into one another,

then spill over the little girl,

resting, ever faithful,

bathed in morning light.

\section{Anne Merritt BA MD}

Resident

Emergency medicine

Yale-New Haven Hospital

New Haven, Conn.

CMAJ 2011. DOI:10.1503/cmaj.100791 